\title{
An Online KAP Study to Access Contraceptive Use Among Reproductive Females in North-Western India
}

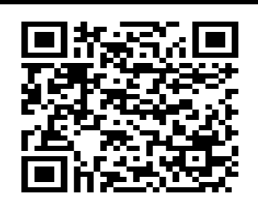

NAVEEN VERMA', JOHN KARTHIK², SAMEER JAIN3

INTRODUCTION: The use of contraceptives has been practiced since thousand of years and if used correctly can lead to birth control.

AIM: To assess the knowledge, attitude and practices of contraceptive of reproductive females aged 18 years and above.

MATERIALS AND METHOD: The present study was cross-sectional in nature and included married females above 18 years of age were asked to fill up an online questionnaire, divided into 4 sections and containing 17 questions. After application of descriptive statistics, the multivariate logistic regression and Pearson's correlation was applied. p value was significant when it was $\leq 0.05$

RESULTS: Most respondents has poor knowledge (54.5\%) of contraceptives with the most preferred method of contraception being OCP $(36.3 \%)$ closely followed by condoms $(36.1 \%)$. Awareness regarding emergency use on contraceptives was mostly seen to be poor $(43.9 \%)$. The most common method used for contraception was condoms ( $49.7 \% \%)$, followed by IUDs (15.6\%), Injectables $(14.3 \%)$ and OCPs(12.7\%). Only a few (5.3\%) did not practice any method for contraception and $2.4 \%$ underwent sterilization. the multivariate logistic regression revealed a significant relation $(\mathrm{p}=0.03)$ while and Pearson's correlation $(\mathrm{p}=0.76)$ revealed a strong association.

CONCLUSION: There is a need to educate females more about the various methods of contraception to promote their reproductive health

KEYWORDS: Contraceptives, Reproductive Health, Unplanned Pregnancy

\section{INTRODUCTION}

As per current estimates, global population is expected to reach 9.2 billion from the current 6.7 billion by the year in 2050. ${ }^{1}$ Such an increase in population shall burden the existing infrastructure as well as nutrition, healthcare and overall well-being of a population. To combat the effects of such a mammoth rise in population, governments have included family planning as a part of their population control initiative.

Fertility control since beginning has been used in different forms with coitus interruptus (withdrawal) being the oldest known method to man., ${ }^{2,3}$ Research estimates that even in today's modern times, approximately 222 million couples do not use any type of contraceptives; and this primarily is due to the lack of the required knowledge and means as well as taboos and beliefs associated with use of various methods of contraception. ${ }^{4}$

Across the globe, the concept of "family planning" is promoted by various governments and organizations as a mechanism to address the reproductive health needs of men and women and to combat the rise in population. ${ }^{5}$ This concept uses the practice of spacing between each child (in years) through the use of contraceptive methods; and this idea is supported by the fact that among women with unintended pregnancies, approximately $60 \%$ of them were not using any form of contraception. ${ }^{6,7}$ It was also found out that among these women, about $12.4 \%$ of them relied on ineffective traditional methods for contraception. ${ }^{8}$

Due to a lack of effective contraceptive options for men (mostly in the form of condoms, withdrawal methods and vasectomy), it is women who nearly have to bear the responsibility for fertility regulation. ${ }^{9}$ It has been documented that the proportion of couples using one or more contraceptive technique in developing countries fluctuate between $20 \%$ and $60 \% .^{10}$

Unplanned pregnancies often result in induced abortion, which poses a major challenge to the reproductive health of young adults in developing countries like India.11 It is important that females of reproductive age have adequate knowledge of various methods used of contraception to prevent any 
unplanned pregnancies, which can affect their health significantly and hence, the present study aimed to assess the knowledge, attitude and practices of contraceptive of married females aged 18 years and above.

\section{MATERIALS AND METHOD}

The present study adopted a cross sectional design and conducted over a period of three months (April 2020 to June 2019) through distribution of an online questionnaire using google forms (Link displayed at various PHCs, Government and Private Hospitals as well as social media) and focussed on women in North Western India. The link was shared with the maximum sample possible and also distributed on social media sites.

The study was approved by the Institutional Ethical Board and upon clicking the link and/or the QR code, the first page assured the females of the confidentiality of their data. The females were free to leave the questionnaire in between and incomplete responses were excluded from the study.

Designing of the questionnaire: The questionnaire was pre-tested and pre-validated prior to its distribution. It contained four sections comprising of a total of 17 Questions (Knowledge: 7, Attitude: 6, Practice: 4) was also available in Hindi to overcome any language barrier. The translation in hindi was done by a language expert and back translated by another, blinded translator. Every correct answer was awarded 1 mark, while incorrect answers were given o marks. Respondents receiving $\geq 14$ marks were considered having good knowledge, $\geq 8$ were considered to have fair knowledge while a score below 8 was classified as having poor knowledge.

Study population: Married females between 18-45 years served as inclusion criteria, while unmarried females were excluded.

Statistical Analysis: After application of descriptive statistics, the multivariate logistic regression and Pearson's correlation was applied. $\mathrm{p}$ value was significant when it was $\leq 0.05$.

\section{RESULTS}

In was observed that among the 551 complete responses received, most respondents has poor knowledge $(54.5 \%)$, followed by fair $(25.2 \%)$ and poor $(20.3 \%)$ knowledge. The most known contraceptive method was
Oral Contraceptive Pills (OCP) (36.3\%) closely followed by condoms (36.1\%). Awareness regarding emergency use on contraceptives was mostly seen to be poor (43.9\%). Social media $(29.8 \%)$ was the main source of information on contraceptive use while $9.5 \%$ were provided information by their parents/family (Table 1 ).

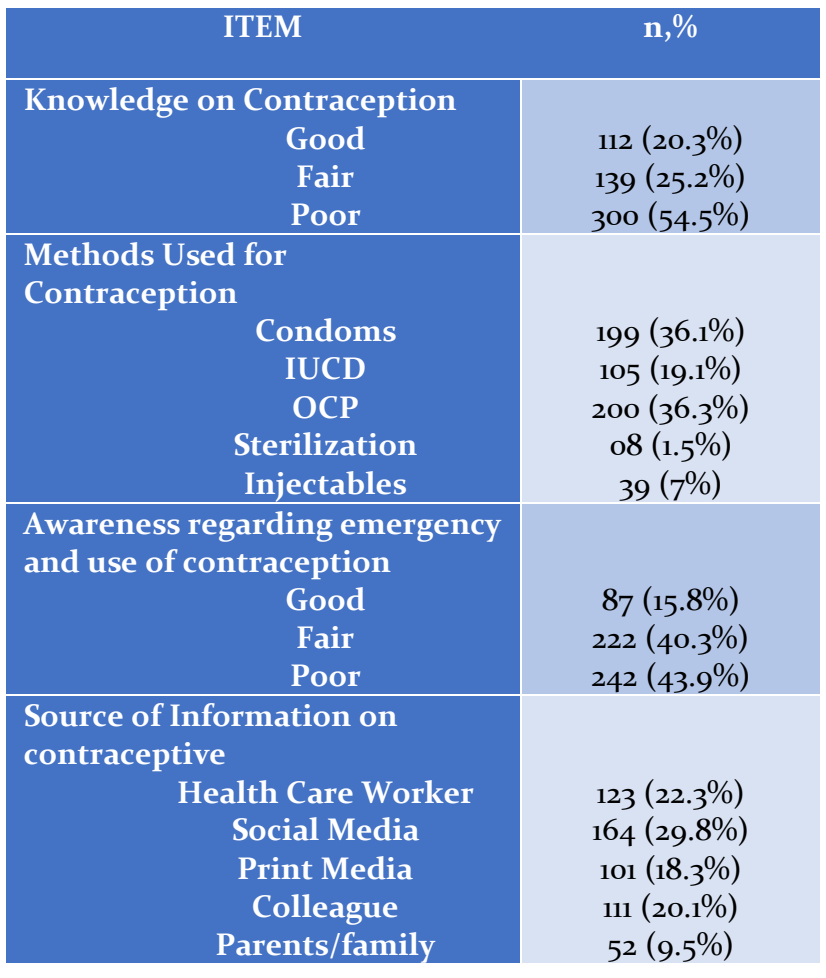

Table 1. Knowledge, Methods, Awareness and Source of Information among Females

It was observed that the most common method used for contraception was condoms $(49.7 \% \%)$, followed by IUDs (15.6\%), Injectables (14.3\%) and OCPs (12.7\%). Only a few $(5.3 \%)$ did not practice any method for contraception and $2.4 \%$ underwent sterilization (Table 2).

\begin{tabular}{|c|c|}
\hline $\begin{array}{c}\text { Method Used for } \\
\text { contraception }\end{array}$ & $\mathbf{n , \%}$ \\
\hline None & $29(5.3 \%)$ \\
\hline Condoms & $274(49.7 \%)$ \\
\hline OCPs & $70(12.7 \%)$ \\
\hline IUDs & $86(15.6 \%)$ \\
\hline Sterilization & $13(2.4 \%)$ \\
\hline Injectables & $79(14.3 \%)$ \\
\hline
\end{tabular}

Table 2. Methods Used for Contraception among Females 
Upon comparison of the awareness regarding contraceptives, the multivariate logistic regression revealed a significant relation $(\mathrm{p}=0.03)$ while and Pearson's correlation $(\mathrm{p}=0.76)$ revealed a strong association. However, comparison of knowledge and use of contraceptives did not bear any significant results (Table 3 ).

\begin{tabular}{|c|c|c|}
\hline & $\begin{array}{c}\text { Multivariate } \\
\text { Logistic } \\
\text { Regression }\end{array}$ & $\begin{array}{l}\text { Pearson's } \\
\text { Correlation } \\
\text { (r) }\end{array}$ \\
\hline $\begin{array}{l}\text { Awareness on } \\
\text { contraceptives }\end{array}$ & $0.03^{*}$ & 0.76 \\
\hline $\begin{array}{c}\text { Knowledge and } \\
\text { use of } \\
\text { contraceptive }\end{array}$ & 1.32 & 0.34 \\
\hline
\end{tabular}

Table 3. Comparison of Awareness Regarding Contraceptives

\section{DISCUSSION}

The findings of the present study revealed that most females (54.5\%) of reproductive age in India had poor knowledge on the various methods of contraception used for family planning. In contrast, good knowledge scores regarding contraceptives were reported by $63.0 \%$ females in Nigeria ${ }^{12}$ as well as $87 \%$ females in Shillong, Meghalaya, India. ${ }^{13}$ Such poor knowledge can be due to the fact that even with various technological advancements in India, the use of "Sex Education" in schools is limited and talking about contraceptives in itself is considered as a social taboo due to various religious beliefs.

Knowledge gained regarding contraceptives among females in the present study was mainly from social media $(29.8 \%)$ followed by healthcare worker $(22.3 \%)$ or a colleague $(22.3 \%)$. Similar results were reported by Sweya MN et al. [friends(44.8\%), television (40.3\%), and health care workers (39.0\%)]. ${ }^{14}$ Also in agreement, females in the study population of Pegu et al. ${ }^{13}$ reported their knowledge from health workers $(58.6 \%)$, followed by media (24.1\%) and social circle(15.5\%).

It was reported that $5.3 \%$ of the females did not use any method of contraception. These finding are in disagreement to Thapa $\mathrm{P}$ et al. (70.8\% of the women reported of having ever used any type of contraceptives) as well as various other studies indicating a high promotion but low utilization of contraceptives, making this situation a serious challenge in developing countries. The most common type of contraceptive in the present study was found to be condoms (49.7\%), which is in agreement to various authors. $9^{9,12,14}$

The present study is prone to certain limitations. The first being the inadvertent social desirability bias and the second being the under-over-reporting of the data by the respondents. To eliminate the bias, no personal data (except for location) was collected and confidentiality of data was assured.

\section{CONCLUSION}

Based on the results of the present study, there is a need to educate females more about the various methods of contraception to promote their reproductive health as well as to avoid any unplanned pregnancies and complications arising from induced abortions.

\section{REFERENCES}

1. Hammad AQ, Hashmi A, Syed AR, Jamil AS, Aslam G. Contraceptive methods and factors associated with modern contraceptive in use. J Family Reprod Health. 2010;4(1):41-46.

2. Ezeh AC, Bongaarts J, Mberu B. Global population trends and policy options. Lancet. 2012;380:142-148.

3. Aldabbagh RO, Al-Qazaz HK. Knowledge and Practice of Contraception Use Among Females of ChildBearing Age in Mosul, Iraq. International Journal of Women's Health 2020;12:107-113

4. Cleland J, Bernstein S, Ezeh A, Faundes A, Glasier A, Innis J. Family planning: the unfinished agenda. Lancet. 2006;368(9549):1810-1827. doi:10.1016/So1406736(06)69480-4

5. Pandey S, Karki S, Pradhan A (2010) Practice of contraceptives. Journal of Institute of Medicine 31: 3-9.

6. Thapa P, Pokharel N, Shrestha M (2018) Knowledge, Attitude and Practices of Contraception among the Married Women of Reproductive Age Group in Selected Wards of Dharan Sub-Metropolitan City. J Contracept Stud Vol.3 No.3:18

7. Duze MC, Mohammed IZ. Male knowledge, attitudes, and family planning practices in Northern Nigeria. Afr J Reprod Health 2006;10:53-65.

8. Oye-Adeniran BA, Adewole IF, Umoh AV, Oladokun A, Ghadegsin A, Ekanem EE, et al. Community-based study of contraceptive behaviour in Nigeria. Afr J Reprod Health 2006;10:90-104

9. Al-Sekait MA. Prevalence of contraception used among Saudi Arabian women. Saudi Med J. 1999;20(9):687-69o.

10. Bearak J, Popinchalk A, Alkema L, Sedgh G. Global, regional, and subregional trends in unintended pregnancy and its outcomes from 1990 to 2014: 
estimates from a Bayesian hierarchical model. Lancet Glob Health. 2018;6(4):e38o-e389. doi:10.1016/S2214109X(18)30029-9

11. Anupama Srivastav, Mohammad Shams Khan, Chitra Rani Chauhan. "Knowledge, Attitude and Practices about Contraceptive among Married Reproductive Females". International Journal of Scientifi c Study. 2014;1(5):2-4.

12. Osaro BO, Tobin-West CI, Mezie-Okoye MM. Knowledge of modern contraceptives and their use among rural women of childbearing age in Rivers State Nigeria. Ann Trop Med Public Health 2017;10:1043-8 13. Pegu B, Gaur BPS, Sharma N, Singh AS. Knowledge, attitude and practices of contraception among married women. Int J Reprod Contracept Obstet Gynecol. 2014;3:385-8. 10.5455/2320-1770.ijrcog20140620
14. Sweya MN, Msuya SE, Mahande MJ, Manongi R. Contraceptive knowledge, sexual behavior, and factors associated with contraceptive use among female undergraduate university students in Kilimanjaro region in Tanzania. Adolesc Health Med Ther. 2016;7:109-115.

https://doi.org/10.2147/AHMT.S108531

15. Haque Md N. Unmet need for contraceptive: the case of married adolescent women in Bangladesh. Int J Curr Res 2010:29-35.

\section{AUTHOR AFFILIATIONS: $\left({ }^{*}\right.$ Corresponding Author $)$}

\section{MD (Preventive and Social Medicine), Private Practitioner and Consultant Doctor, Nahan, HP, India \\ 2. MD (Preventive and Social Medicine), Private Practitioner and Consultant Doctor, Hyderabad, Telangana, India 3. MBBS, Consultant Surgeon, Bhopal, Madhya Pradesh, India}

Source of support: Nil, Conflict of interest: None declared 